\title{
ANALISIS IMPLEMENTASI GOOD CORPORATE GOVERNANCE DAN PENERAPAN PSAK NO.109 TENTANG AKUNTANSI ZAKAT PADA LEMBAGA AMIL ZAKAT YAYASAN SOLOPEDULI UMMAT
}

\author{
Anggit Kartika Candraningsih, Endang Masitoh Wahyuningsih, Purnama Siddi \\ Fakultas Ekonomi Jurusan Akuntansi Universitas Islam Batik Surakarta \\ Email : tika.ak21@gmail.com
}

\begin{abstract}
In this study aims to test and analyze the Amil Zakat Institution Solopeduli Foundation has implemented the principles of Good Corporate Governance and test the consistency of the presentation of zakat and infaq / alms accounting at the Amop Zakat Institution Solopeduli Foundation in accordance with PSAK No. 109. The results of this study indicate that the Implementation of Good Corporate Governance and SFAS 109 at the Solopeduli Foundation have been effectively implemented. The management of zakat, donation / alms in the Solopeduli Foundation has referred to the principles of Good Corporate Governance and in its financial recording and reporting refers to PSAK 109 so as to create effectiveness in the management of zakat, infaq / alms. The distribution of zakat is based on the priority scale of the Solopeduli Foundation prioritizing the Orphans and the Poor. This study aims to determine the effect of Return On Assets, Price.
\end{abstract}

Keywords: GCG, PSAK 109, Solopeduli Ummat Foundation, Amil Zakat.

\section{PENDAHULUAN}

Indonesia adalah Negara yang mayoritas penduduknya muslim, banyak organisasi yang berbasis Islam didirikan oleh sekelompok orang ataupun golongan yang mempunyai kepentingan baik bisnis maupun sosial. Indonesia secara demografi dan kultural memiliki potensi yang layak dikembangkan menjadi salah satu instrumen pemerataan pendapatan khususnya masyarakat muslim, yaitu institusi Zakat, Infak dan Sedekah (Hasbar \& Kurnia, 2016).

Dalam UU nomor 23 Tahun 2011 tentang pengelolaan zakat dijelaskan bahwa negara menjamin kemerdekaan tiap-tiap penduduk untuk memeluk agamanya masing-masing dan untuk beribadah menurut agamanya dan kepercayaan itu. Zakat adalah salah satu rukun islam yang wajib hukumnya bagi setiap muslim yang merdeka dan memiliki harta kekayaan sampai dengan jumlah tertentu yang telah mencapai nisab (Nurhayati, Sari, \& Wasilah, 2013).

Tujuan dan sasaran Lembaga Amil Zakat (LAZ) dapat dicapai melalui tata kelola secara efektif, profesional, dan bertanggungjawab. Suatu standar akuntansi diperlukan untuk dijadikan patokan dalam pelaporan keuangan sekaligus untuk pelaksanaan dan pengelolaan zakat yang sesuai kaidah syariah. Sejalan dengan hal tersebut IAI telah mengeluarkan Pernyataan Standar Akuntansi Keuangan (PSAK No. 109) tentang Akuntansi Zakat dan Infak/Sedekah yang disahkan dan berlaku efektif pada tahun buku 1 januari 2012 (Irpansyah, Rahmi, \& Helmi, 2013).

Dalam mencapai tata kelola perusahaan yang profesional dan efisien, maka diperlukan Good Corporate Governance (GCG), merupakan prinsip yang mengarahkan dan mengendalikan perusahaan agar mencapai keseimbangan antara kekuatan serta kewenanangan dalam memberikan pertanggungjawaban kepada para shareholder khususnya, dan stakeholder pada umumnya (Atsarina, 2018).

Berdasarkan uraian tersebut maka peneliti merumuskan masalah sebagai berikut : (1) Apakah Lembaga Amil Zakat Yayasan Solopeduli telah mengimplementasikan prinsip-prinsip dari Good 
Corporate Governance ? (2) Apakah penerapan penyajian akuntansi zakat dan infak/sedekah di Lembaga Amil Zakat Yayasan Solopeduli konsisten dengan PSAK No. 109 ?. kemudian tujuan dari penelitian ini adalah (1) Menguji dan menganalisis Lembaga Amil Zakat Yayasan Solopeduli telah mengimplementasikan prinsip-prinsip dari Good Corporate Governance. (2) Menguji konsistensi penyajian akuntansi zakat dan infak/sedekah di Lembaga Amil Zakat Yayasan Solopeduli sesuai dengan PSAK No. 109.

\section{KERANGKA TORITIS DAN PENGEMBANGAN HIPOTESIS}

A. Kerangka Teoritis

1. Pengertian Good Corporate Governance

Beberapa intitusi di Indonesia mengajukan beberapa definisi Corporate Governance (CG), antara lain dari keputusan menteri badan usaha milik negara pasal 1 surat KEPMEN nomor KEP-177/M-MBU/2002 tgl 31 Juli 2002, Corporate Governance adalah suatu proses dari stuktur yang digunakan oleh BUMN untuk meningkatkan keberhasilan usaha dan akuntabilitas perusahaan demi mewujudkan nilai pemegang saham dalam jangka panjang dengan tetap memperhatikan kepentingan stakeholder lainnya, berlandaskan peraturan perundangan dan nilai-nilai etika.

2. Konsep Zakat

Kata zakat berasal dari bahasa arab yang memiliki arti yang bervariasi. Istilah zakat berasal dari kata "zaka" yang berarti suci, jernih, bersih, berkah, berkembang, bertumbuh, bertambah, cerdik, dan terpuji. Dalam ensiklopedia Indonesia zakat berarti tumbuh, berkembang, bersih atau baik dan terpuji. Arti kata bersih suci dalam istilah zakat memberi makna membersihkan harta / membersihkan diri dari sifat tamak, dengki, dendam, dan bakhil.

B. Pengembangan Hipotesis

Berdasarkan tinjauan pustaka, penelitian terdahulu dan kerangka pemikiran maka hipotesis dalam penelitian ini adalah implementasi Good Corporate Governance dan penerapan PSAK No. 109 tentang akuntansi zakat pada Solopeduli telah dilaksanakan secara efektif.

\section{METODOLOGI PENELITIAN}

A. Variabel Penelitian

1. Good Corporate Governance (GCG)

Indikator pengukuran data implementasi Good Corporate Governance :

a. Transparansi (Tranparancy).

Transparansi Prinsip dasar yang berfungsi menjaga objektifittas dalam pengelolaan suatu lembaga, perusahaan harus menyediakan informasi yang material dan relevan dengan cara yang mudah diakses dan dipahami oleh pemangku kepentingan.

2. Pengukuran indikator PSAK No. 109:

a. Pengungkapan ketentuan dari PSAK No. 109 berupa Mustahik adalah orang atau entitas yang berkah menerima zakat. Mustahik terdiri dari: fakir, miskin, riqab, orang yang terlilit hutang (gorim), mualaf, fisabilillah,orang yang dalam perjalanan jauh (ibnu sabil), dan amil.

b. Pengukuran ketentuan dari PSAK No. 109 berupa penentuan nilai wajar aset non kas yang diterima menggunakan harga pasar, jika tidak tersedia, maka dapat menggunakan metode penentuan nilai wajar lainnya sesuai dengan SAK yang relevan.

c. Pengakuan ketentuan dari PSAK No. 109 berupa penerimaan zakat diakui pada saat kas atau aset non kas diterima. 
d. Penyajian ketentuan dari PSAK No. 109 berupa penyajikan dana zakat, dana infak/sedekah dan dana amil secara terpisah dalam pelaporan posisi keuangan.

B. Populasi dan Sampel

Populasi penelitian ini dilakukan pada Lembaga Amil Zakat (LAZ) di Surakarta yaitu Yayasan Solopeduli. Sample dari responden adalah pengurus lembaga zakat di Yayasan Solopeduli Surakarta dan salah satu muzakkidi Yayasan Solopeduli. LAZ Solopeduli dipilih karena termasuk kedalam skala LAZ Provinsi yang berpusat di Surakarta.

C. Jenis dan Sumber Data

Jenis data yang digunakan dalam penelitian ini adalah data subjek yang diperoleh dari wawancara dan data dokumenter. Sedangkan sumber data dalam penelitian adalah data primer dan sekunder. Data primer mengacu pada informasi yang diperoleh langsung oleh peneliti terkait dengan variabel yang terkait dalam penelitian ini (Wiley, 2017). Informan kunci adalah orang yang mengetahui permasalahan pengelolaan dana zakat dan infak/ sedekah. Data sekunder mengacu pada informasi yang dikumpulkan dari sumber-sumber yang sudah ada seperti dalam penelitian ini berupa format laporan keuangan di Lembaga Amil Zakat Yayasan Solopeduli dan studi pustaka lainnya berupa penelitian terdahulu yang dianggap relevan untuk penelitian ini.

D. Instrumen Penelitian

Instrumen dari penelitian ini terdiri dari instrumen utama dan instrumen penunjang. Sesuai dengan pendekatan kualitatif yang digunakan maka kehadiran peneliti di lapangan sangat penting dan menentukan. Peneliti bertindak sebagai instrumen utama sekaligus sebagai pengumpul data penelitian. Instrumen penunjang berupa rekaman, kamera, serta daftar pertanyaan yang sudah disiapkan sebelumnya.

E. Metode Analisa Data

Dalam penelitian ini, informasi yang telah terkumpul akan di peroleh dengan metode analisis adalah deskriptif analitis karena bertujuan memberikan gambaran secara menyeluruh, mendalam tentang suatu keadaan atau gejala yang diteliti.

F. Metode Pengumpulan Data

Metode yang digunakan dalam penelitian ini adalah sebagai berikut:

1) Wawancara.

Wawancara merupakan teknik pengumpulan data yang dilakukan untuk mengetahui hal-hal dari responden secara mendalam. Wawancara yang dilakukan adalah komunikasi secara langsung (tatap muka) antara pewawancara dengan responden.

2) Dokumentasi

Dokumen yang digunakan dalam penelitian ini berupa foto, gambar, serta data-data mengenai objek penelitian. Dokumentasi bermanfaat untuk menyediakan data dalam penelitian.

3) Studi pustaka

Studi pustaka adalah teknik pengumpulan data dengan menggunakan referensi buku, jurnal, PSAK, dan perundang-undangna terkait dengan objek penelitian untuk mendapat konsep dan data-data yang relevan.

4) Internet Searching

Internet searching merupakan penelitian yang dilakukan dengan mengumpulkan data yang bersumber dari internet guna melengkapi referensi penulis serta untuk menemukan fakta atau teori yang berkaitan dengan penelitian.

G. Teknik Analisa Data

Proses analisis data dilakukan sejak pengumpulan data sampai selesainya proses pengumpulan data. Adapun proses-proses tersebut dijelaskan dalam tiga tahap berikut: 
(1) Reduksi data dilakukan dengan berfokus pada pencarian materi penelitian dari berbagai literatur yang digunakan sesuai dengan pokok masalah yang telah diajukan pada rumusan masalah.

(2) Penyajian data yang digunakan peneliti adalah dengan menggunakan metode deskriptif.

(3) Penarikan kesimpulan dari pengumpulan data dan analisis yang telah dilakukan, maka peneliti selanjutnya mencari makna dari setiap gejala yang diperolehnya dalam proses penbelitian, mencatat keterbatasan yang dihadapi dalam penelitian dan implikasi positif diharapkan bisa diperoleh dari penelitian ini.

H. Pengujian keabsahan data

Penelitian ini menggunakan berbagai sumber data dan teori dalam menghasilkan data dan informasi yang akurat, maka cara yang tepat digunakan adalah dengan menggunakan metode Triangulasi. Metode trianguasi merupakan teknik yang juga sering dihubungkan dengan penggunaan metode campuran. Ide dibalik triangulasi adalah bahwa seseorang dapat lebih yakin dengan temuannya jika penggunaan metode atau sumber yang berbeda menghasilkan temuan yang sama. Triangulasi mengharuskan bahwa penelitian berhubungan dengan berbagai jenis prespektif (Wiley, 2017, hal. 119).

\section{HASIL DAN PEMBAHASAN}

1. Implementasi Prinsip-prinsip Good Corporate Governance (GCG) Dalam Pengelolaan Zakat di Yayasan Solopeduli.

Tabel 1

Implementasi Prinsip Transparansi di Lembaga Amil Zakat Yayasan Solopeduli

\begin{tabular}{|c|c|c|}
\hline Prinsip - prinsip $\quad$ GCG & Indikator & $\begin{array}{l}\text { Implementasi di Yayasan } \\
\text { Solopeduli }\end{array}$ \\
\hline \multirow[t]{3}{*}{$\begin{array}{l}\text { Transparansi } \\
\text { (Transparancy) }\end{array}$} & $\begin{array}{l}\text { 1. Rencana kerja } \\
\text { tahunan. }\end{array}$ & $\begin{array}{l}\text { 1. Yayasan Solopeduli } \\
\text { selalu membuat } \\
\text { rencana kerja tahun } \\
\text { an. }\end{array}$ \\
\hline & $\begin{array}{l}\text { 2. Laporan keuangan } \\
\text { tahunan. }\end{array}$ & $\begin{array}{l}\text { 2. Bagian keuangan } \\
\text { membuat laporan } \\
\text { triwulan jika atasan } \\
\text { meminta dengan } \\
\text { melampirkan laporan } \\
\text { akhir bulan } \\
\text { sebelumnya, laporan } \\
\text { tahunan untuk } \\
\text { diaudit. }\end{array}$ \\
\hline & $\begin{array}{l}\text { 3. Sistem akuntansi } \\
\text { berbasis standar } \\
\text { akuntansi. }\end{array}$ & $\begin{array}{l}\text { 3. Yayasan Solopeduli } \\
\text { menggunakan standar } \\
\text { akuntansi dalam } \\
\text { pencatatan dan }\end{array}$ \\
\hline
\end{tabular}




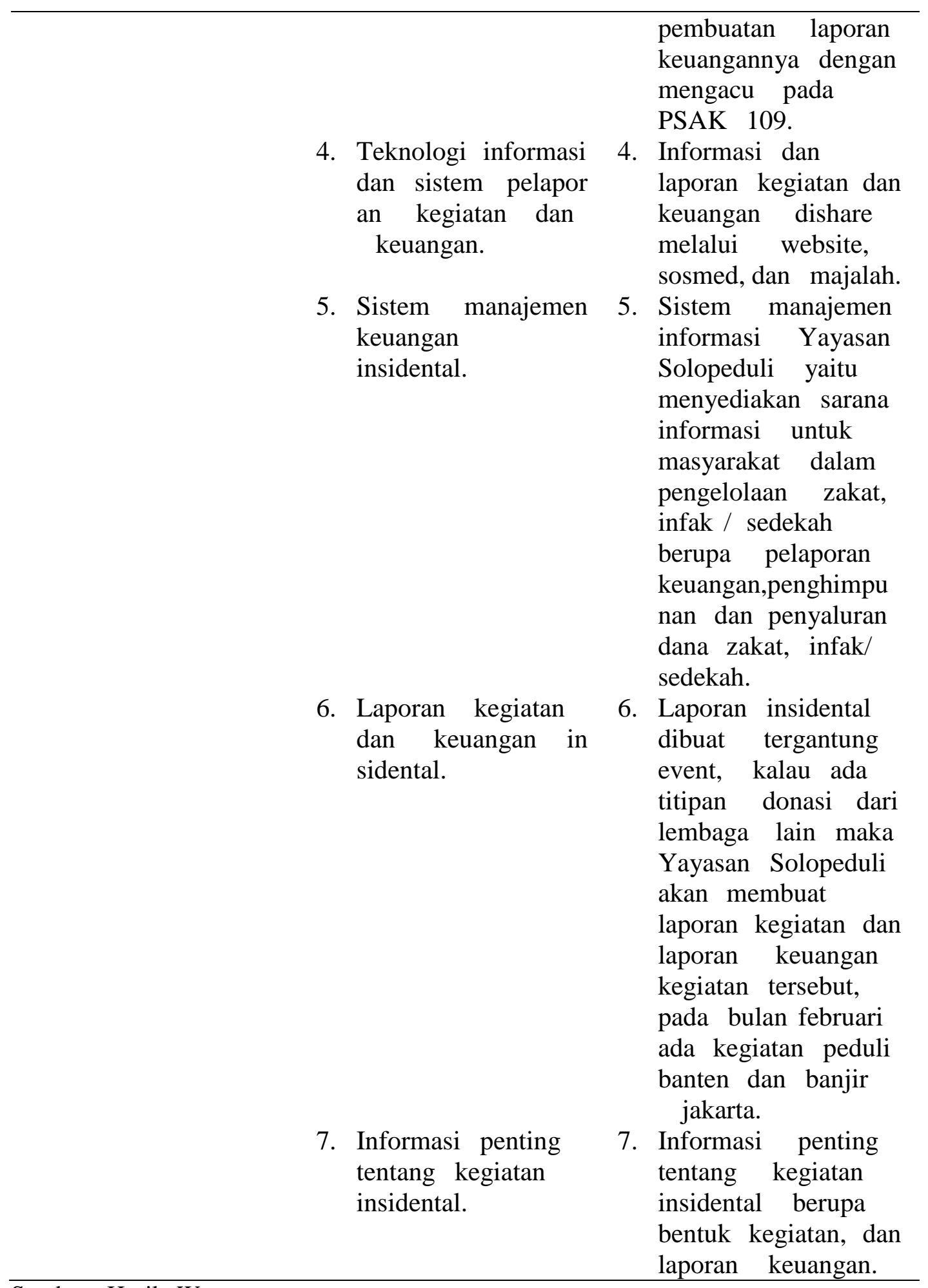

Sumber : Hasil Wawancara. 
Tabel 2

Implementasi Prinsip Akuntabilitas (Accountability)

di Lembaga Amil Zakat Yayasan Solopeduli

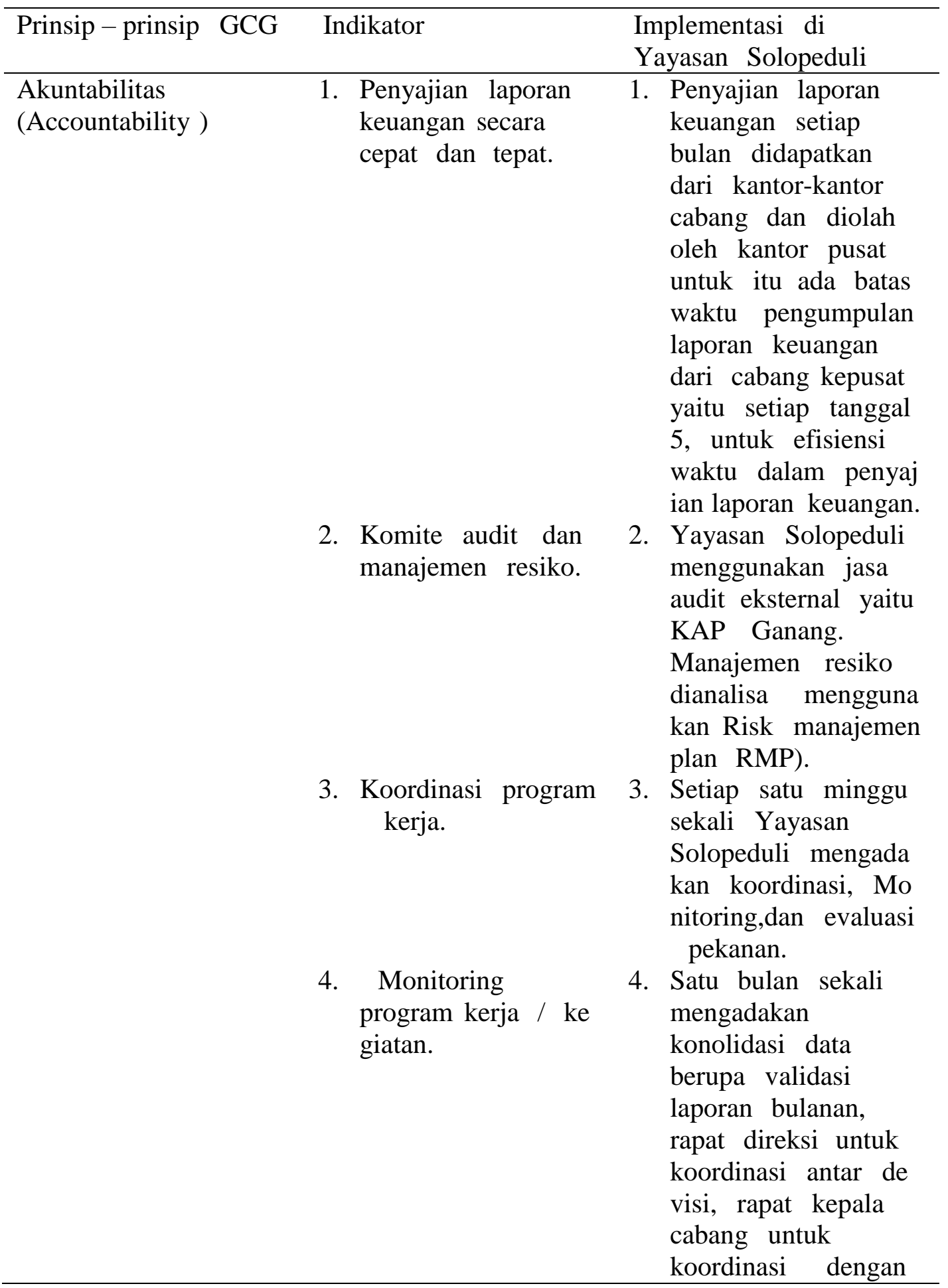




\begin{tabular}{ll}
\hline & para kepala kantor \\
cabang. Pleno evalua \\
si 1 semester dilak \\
sanakan setiap 6 \\
bulan sekali.
\end{tabular}

Sumber : Yayasan Solopeduli.

Tabel 3

Implementasi Prinsip Responsibilitas (Responsibility) di Lembaga Amil Zakat Yayasan Solopeduli

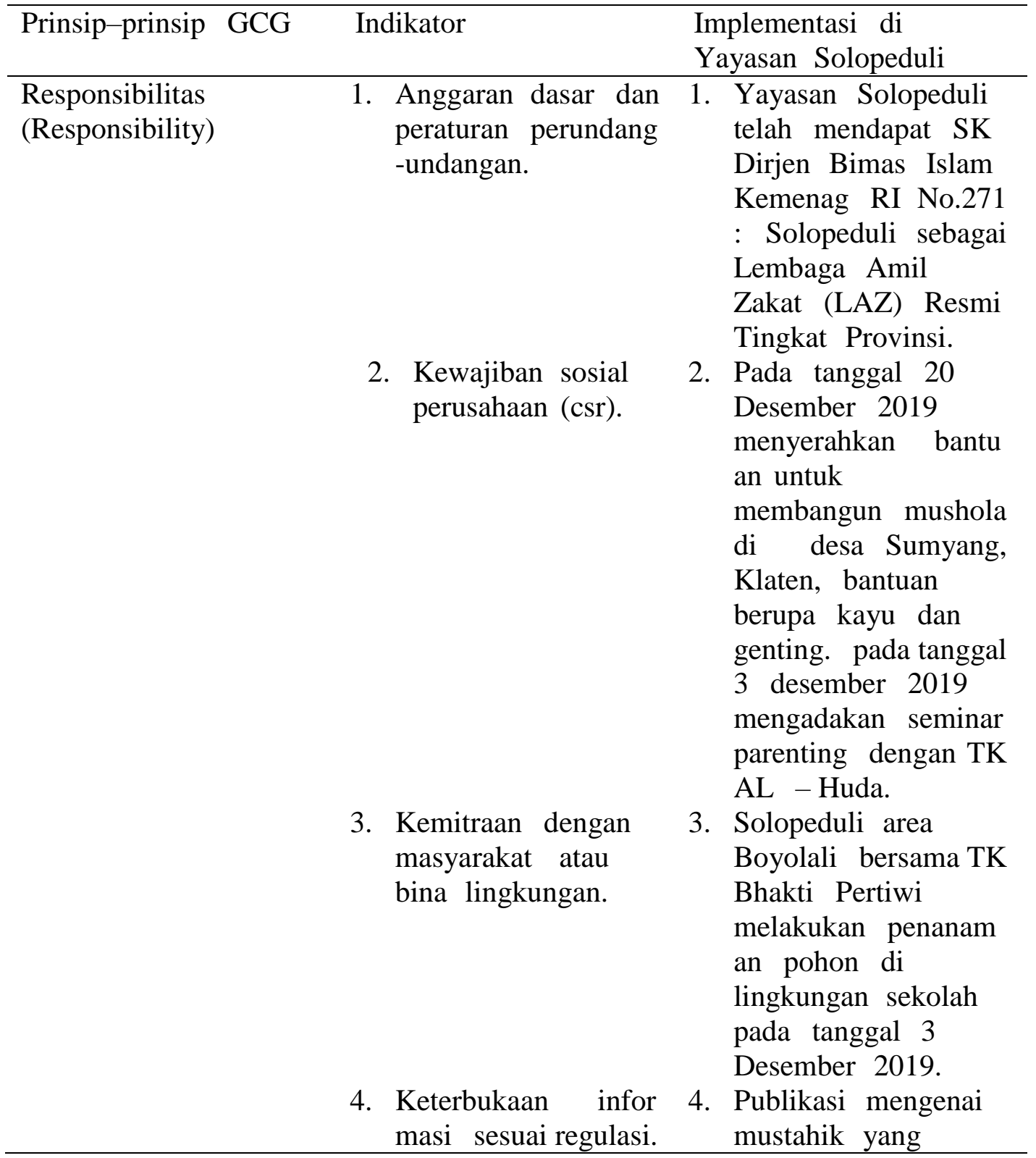




\begin{tabular}{ll}
\hline & menerima bantuan \\
yaitu dengan & meminta izin \\
mustahik agar tidak & tersinggung. Untuk \\
& publikasi laporan \\
& keuangan akan \\
& dipublikasi setelah \\
& laporan di audit oleh \\
& pihak audit. \\
& Penerapan etika, \\
& moral dan akhlak di \\
Etika, moral dan & Yayasan Solopeduli \\
& yaitu dengan \\
& mengimplementasikan \\
& SOP pelayanan dan \\
& pengelolaan zakat \\
& serta setiap pekan \\
& diadakan pembinaan \\
& karyawan sebagai \\
& upaya untuk \\
& menjaga etika, \\
& moral dan akhlak \\
& amil / pengawai. \\
\hline
\end{tabular}

Sumber data: hasil wawancara.

2. Penerapan PSAK 109 Tentang Akuntansi Zakat di Yayasan Solopeduli

Tabel 6

Konsistensi Penerapan PSAK No.109 di Yayasan Soloepduli dari Tahun 2016-2019

\begin{tabular}{|c|c|c|c|c|c|}
\hline No. & $\begin{array}{l}\text { Penjelas } \\
\text { an }\end{array}$ & $\begin{array}{l}\text { Ketentuan } \\
\text { PSAK } \\
\text { No.109 }\end{array}$ & $\begin{array}{l}\text { Penerapan } \\
\text { Yayasan } \\
\text { Solopeduli } \\
\text { (2016) }\end{array}$ & $\begin{array}{l}\text { Penerapan } \\
\text { Yayasan } \\
\text { Solopeduli } \\
(2019)\end{array}$ & Keterangan \\
\hline 1. & $\begin{array}{l}\text { Pengak } \\
\text { uan. }\end{array}$ & $\begin{array}{l}\text { Poin } 10 . \\
\text { Penerimaan } \\
\text { zakat pada } \\
\text { saat kas atau } \\
\text { aset non kas } \\
\text { yang diteri } \\
\text { ma. }\end{array}$ & $\begin{array}{l}\text { Penerirmaan } \\
\text { zakat } \\
\text { diakui dan } \\
\text { dicatat } \\
\text { dalam ben } \\
\text { tuk kas } \\
\text { maupun } \\
\text { barang. }\end{array}$ & $\begin{array}{l}\text { Keuangan } \\
\text { menggunakan } \\
\text { sistem accu } \\
\text { rual basis, } \\
\text { penerimaan } \\
\text { zakat diakui } \\
\text { dan dicatat } \\
\text { pada saat } \\
\text { transaksi }\end{array}$ & Konsisten \\
\hline
\end{tabular}




\begin{tabular}{|c|c|c|c|c|c|}
\hline & & & & $\begin{array}{l}\text { terjadi dan } \\
\text { dicatat dalam } \\
\text { bentuk kas } \\
\text { ataupun bara } \\
\text { ng. }\end{array}$ & \\
\hline 2. & $\begin{array}{l}\text { Pengu } \\
\text { kuran. }\end{array}$ & $\begin{array}{l}\text { Poin } 12 . \\
\text { Penentuan } \\
\text { nilai wajar } \\
\text { aset non } \\
\text { kas yang } \\
\text { diterima } \\
\text { menggunak } \\
\text { an harga } \\
\text { pasar jika } \\
\text { harga pasar } \\
\text { tidak } \\
\text { tersedia, } \\
\text { maka dapat } \\
\text { menggunak } \\
\text { an metode } \\
\text { penentuan } \\
\text { nilai wajar } \\
\text { sesua } \\
\text { dengan SK } \\
\text { yang rele } \\
\text { van. }\end{array}$ & $\begin{array}{l}\text { Pada saat } \\
\text { muzzaki } \\
\text { yang membe } \\
\text { ri donasi } \\
\text { berupa bara } \\
\text { ng, maka } \\
\text { akan } \\
\text { dilakukan } \\
\text { taksiran } \\
\text { sesuai } \\
\text { dengan har } \\
\text { ga pasar. }\end{array}$ & $\begin{array}{l}\text { Pada saat } \\
\text { muzzaki } \\
\text { memberikan } \\
\text { donasi beru } \\
\text { pa barang } \\
\text { maka akan } \\
\text { ditaksir sesuai } \\
\text { dengan harga } \\
\text { pasar saat } \\
\text { ini berlaku. }\end{array}$ & Konsisten. \\
\hline 3. & $\begin{array}{l}\text { Panyaji } \\
\text { an. }\end{array}$ & $\begin{array}{l}\text { Poin } 38 . \\
\text { Amil } \\
\text { menyajikan } \\
\text { dana zakat, } \\
\text { infak / sede } \\
\text { kah } \\
\text { dan dana } \\
\text { amil terpisa } \\
\text { h dalam } \\
\text { pelaporan } \\
\text { posisi } \\
\text { keuangan. }\end{array}$ & $\begin{array}{l}\text { Solopeduli } \\
\text { menyajikan } \\
\text { dana zakat, } \\
\text { dana infak } \\
\text { / sedekah } \\
\text { dan dana } \\
\text { amil } \\
\text { terpisah } \\
\text { pada laporan } \\
\text { posisi keuan } \\
\text { gan. }\end{array}$ & $\begin{array}{l}\text { Pada laporan } \\
\text { posisi keuang } \\
\text { an yayasan } \\
\text { solopeduli } \\
\text { dana zakat, } \\
\text { infak / sedek } \\
\text { ah, dana amil } \\
\text { disajikan } \\
\text { secara } \\
\text { terpisah. }\end{array}$ & Konsisten. \\
\hline 4. & $\begin{array}{l}\text { Pengun } \\
\text { gkapan. }\end{array}$ & $\begin{array}{l}\text { Poin } 5 . \\
\text { Ketentuan } \\
\text { PSAK } \\
\text { No.109 } \\
\text { berupa } \\
\text { mustahik }\end{array}$ & $\begin{array}{l}\text { Solopeduli } \\
\text { sudah ada } \\
\text { pembagian } \\
\text { sendiri dan } \\
\text { pembagian } \\
\text { khusus }\end{array}$ & $\begin{array}{l}\text { Yayasan } \\
\text { Solopeduli } \\
\text { dalam } \\
\text { pembagian za } \\
\text { kat, } \\
\text { infak / sedek }\end{array}$ & Konsisten. \\
\hline
\end{tabular}




\begin{tabular}{lll}
\hline adalah & untuk zakat & ah diberikan \\
orang atau & ada sendiri & pada 8 \\
entitas yang & dan sudah & golongan \\
berkah & diatur dalam & yang sudah \\
menerima fiqih. & diatur dalam \\
zakat. & Al-Qur'an \\
Mustahik & untuk priorit \\
terdiri dari : & as \\
& fakir, & pembagian \\
& miskin , & diberikan \\
riqa , & pada fakir \\
& orang & dan miskin. \\
yang terlilit & \\
hutang & \\
(gorim), mu & \\
alaf, & \\
& fisabilillah, & \\
orang yang & \\
dalam perja & \\
lanan jauh & \\
(ibnu sabil), & \\
dan amil. & \\
\hline
\end{tabular}

Sumber : Jurnal Penelitian Listiyowati tentang penarapan PSAK No.109 di Yayasan Solopeduli dan Hasil wawancara.

\section{KESIMPULANAN}

Pada penelitian ini bertujuan untuk menguji dan menganalisis Lembaga Amil Zakat Yayasan Solopeduli telah mengimplementasikan prinsip-prinsip dari Good Corporate Governance dan menguji konsistensi penyajian akuntansi zakat dan infak /sedekah di Lembaga Amil Zakat Yayasan Solopeduli sesuai dengan PSAK No. 109. Hasil penelitian ini menunjukan bahwa Penerapan Good Coorporate Governance dan PSAK 109 di Yayasan Solopeduli telah efektif dilaksanakan.

\section{Daftar Pustaka}

Al-Qur'an.

Anwar, A. S. (2012). Model Tata Kelola Badan dan Lembaga Amil Zakat Sebagai Upaya Untuk Meningkatkan Pemberdayaan Ekonomi Masyarakat (Studi Pada Badan/ Lembaga Amil Zakat di Kota Malang). Jurnal Humanity, Vol 7, 1-13.

Arief, S. W., Manossoh, H., \& Alexsander, S. W. (2017). Analisa Penerapan PSAK 109 Tentang Akuntansi Zakat Infaq/sedekah Pada Badan Amil Zakat Nasional Kota Manado. Jurnal Riset Akuntansi Going Corner, 98-107. 
Atsarina. (2018). Analisa Penerapan Good Corporate Governance Pada Organisasi Pengelola Zakat (Studi kausus di Badan Amil Zakat dan Dompet Dhuafa). Menara Ekonomi, Vol 1.

Habib, A. A. (2016). The Principle of Zakat, Infaq, and Shadaqah Accounting Based Sfas 109. Jurnal of Accounting and Business Education .

Hafidhuddin, D., \& Tanjung, H. (2003). Manajemen Syariah dalam Praktik. Jakarta: Gema Insani Press.

Handayani, S. (2019). Akuntansi Zakat PSAK 109 dalam Penguatan Good Corporate Lembaga Amil Zakat di Kabupaten Pamekasan. Istishadia: Jurnal Ekonomi dan Perbankan Syariah , 193-201.

Hasbar, H. M., \& Kurnia, N. G. (2016). Analisis Implementasi Good Corporate Governance dan Penerapan PSAK 109 Tentang Akuntansi Zakat pada Lembaga Amil Zakat Dompet Dhuafa Cabang Sulawesi Selatan. AKMEN Jurnal Ilmiah .

Hasiara, L. O., Mesra, N. A., \& Diah, A. M. (2019). The EFffect of Good Corporate Governance in Accounting on Muzzaki Statisfaction at Amil Zakat Institusion (LAZ Dpu) of East Kalimantan Samarinda Barnch-Indonesia. International Of Journal Scientific and Thecnology Research , 831-837.

Indrarini, N. (2017). jurnal akuntansi. transparansi dan akuntabilitas laporan lembaga amil : perspektif muzaki upz bnisyariah, vol 8 no2.

Irpansyah, Rahmi, \& Helmi. (2013). Studi Penerapan Akuntansi Zakat pada BAZNAS Provinsi Kalsel dan BAZNAS Banjarmasin. Taswir .

Istutik. (2013). Analisis Implementasi Akuntansi Zakat, Infak dan Sedekah (PSAK:109) Pada Lembaga Amil Zakat di Kota Malang. Jurnal Akuntansi Aktual , 19-24. 